\title{
Differences in Maturity, Morphological, AND Fitness Attributes Between the Better- AND Lower-Ranked Male and Female U-14 Portuguese Elite Regional Basketball Teams
}

\author{
Sérgio Ramos, ${ }^{1}$ Anna Volossovitch, ${ }^{2}$ António P. Ferreira, ${ }^{2}$ Carlos Barrigas, ${ }^{2}$ \\ Isabel Fragoso, ${ }^{2}$ and Luís Massuça ${ }^{1,2,3}$ \\ ${ }^{1}$ Faculty of Physical Education and Sport, Lusófona University, Lisbon, Portugal; ${ }^{2}$ CIPER, Faculty of Human Kinetics, \\ University of Lisbon, Cruz-Quebrada, Portugal; and ${ }^{3} I C P O L$, Higher Institute of Police Sciences and Internal Security, Lisbon, \\ Portugal
}

\begin{abstract}
Ramos, S, Volossovitch, A, Ferreira, AP, Barrigas, C, Fragoso, $I$, and Massuça, L. Differences in maturity, morphological and fitness attributes between the better- and lower-ranked male and female U-14 Portuguese elite regional basketball teams. J Strength Cond Res XX(X): 000-000, 2018-During a national championship, the anthropometric, physiological, and maturation attributes of 13-14-year-old players of regional selection basketball teams and their association with team's final classification were analyzed. Body parameters (weight, height, skinfolds, and lengths) were measured and physiological capacities assessed by sprint $(20 \mathrm{~m})$, agility, jump, and upper-body strength tests. Chronological age, maturity offset (years from age at peak height velocity; YAPHV), and predicted age at peak height velocity were calculated. In both sexes, no significant differences were found for maturity. Anthropometric and physiological analysis indicated that male players from finalist's teams were significantly faster, were more agile, threw the medicine ball longer, and showed lower percentages of body fat than players from lower-ranked teams. Further, semifinalists were faster than lower-ranked players. In the same sense, female players from semifinalist teams demonstrated to be significantly faster, more agile, and threw the medicine ball longer than female players from lower-ranked teams. In addition, discriminant analysis showed that speed (in boys) and the combination of speed and upper limb strength (in girls) could successfully discriminate players with different performances in a championship. In conclusion, speed and upper limb strength appear to be the physical attributes associated with better team performance in youth basketball. Coaches should
\end{abstract}

Address correspondence to Sérgio Ramos, sergio6ramos@hotmail.com. 00(00)/1-10

Journal of Strength and Conditioning Research

(C) 2018 National Strength and Conditioning Association be aware of the relationship between the improvement of these physical attributes and the teaching-learning process of the basketball game.

KEY WoRDS youth basketball, maturation, physical fitness, team performance

\section{INTRODUCTION}

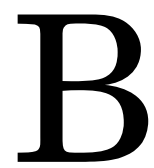

asketball is a dynamic and complex team game that combines explosive movement structures (i. e., short sprints, abrupt stops, fast changes in direction, acceleration, and vertical jumps) with different technical skills, such as dribbling, passing or shooting (12). Success in basketball depends on a variety of factors, among which morphologic (i.e., stature, body mass, arm span, and body composition) (30) and fitness (11) attributes seem to have an important influence on the players' performance.

Motor performance in childhood and adolescence is strongly associated with the growth and maturation processes (21). Individuals with early maturation have an advantage in explosive power, anaerobic power, isometric strength, and sprinting than those whose biological development initiated later $(21,27)$. These differences in motor skills and biological development are most evident in the phases with the more pronounced growth rate (i.e., growth spurt). These phases occur between 12 and 15 years in boys and $10-14$ years in girls (21). Basketball players of these ages are mostly included in under-14 (U-14) category.

It is not surprising that the selection process in youth basketball can be strongly influenced by the maturity process (7) and the development of physical attributes of players $(16,30)$. Several studies reported considerable increases in height, weight, running speed, resistance, agility, and strength during adolescent development $(5,25)$. Although 
the process of talent selection in basketball starts at an early age, literature focuses especially on college and professional senior athletes $(30,39)$. The knowledge about the factors that influence the young players' performance of both sexes needs to be deepened.

Previous studies have found the differences in anthropometry and physiological capacities, and in chronological and biological age among U-14 Spanish male basketball players of different skill levels (36,37). The better-ranked male teams, which participated in the Spanish Basketball Association championship, demonstrated significantly better sprint performance than lower-positioned teams (36). The strong correlation between the individual on-court performance and body length measurements, body composition, and physiological test results has also been reported $(36,37)$. Maturity offset was identified as the best predictor of basketball performance of U-14 basketball players (37).

From the talent development perspective, it would be useful to verify if the findings obtained in Spanish youth basketball would be consistent with studies conducted in other countries and competitive contexts with players of the same age group. In the Portuguese youth basketball, there is no evidence highlighting the relationships between the anthropometric, physical, and maturational characteristics of players and their game performance.

Despite the well-documented physiological and maturational differences between males and females during adolescence $(2,18)$, the literature focuses more on male players and does not provide comprehensive information about the anthropometric and physical attributes of adolescent female basketball players according to their skill level.

To clarify the understanding about the attributes that really discriminate the young male and female basketball players of different skill levels, it is necessary to use more basketball-specific sets of anthropometric measures and physical testing batteries that have been used in previous research.

Thus, the purposes of this study were: (a) to analyze the anthropometric, physical, and maturational attributes of $\mathrm{U}$ 14 basketball players of both sexes, who integrated regional teams, which participated in the 2016 male and female under-14 Portuguese National Basketball Championship, (b) to compare the morphological and physical attributes of players from finalists (classified in first or second place), semifinalists (classified in third or fourth place) and lowerranked teams (classified from fifth to eighth positions for male teams and from fifth to ninth positions for female teams), and (c) to identify the set of morphological and physical attributes which better discriminate the higherpositioned male and female regional teams from lowerpositioned teams which participated in the youth tournament mentioned above. Our hypothesis is that young basketball players with different performances in a championship show different morphological, maturational and physiological attributes.

\section{Methods}

\section{Experimental Approach to the Problem}

Anthropometric and physiological attributes are relevant in youth basketball $(36,37)$. Maturity process can strongly influence the development of physical attributes of basketball players (5) and their individual game performance. To assess the relationships between the anthropometric variables (i.e., height, weight, arm spam, body fat), physiological characteristics (i.e., sprint, agility, upper-body strength and jump capacity), maturity status (i.e.,: maturity offset, years from age at peak height velocity [YAPHV] and predicted age at peak height velocity $[\mathrm{APHV}]$ ) and game performance (i.e., team's final classification) in elite youth basketball, the descriptive comparative design was used. The stepwise discriminant analysis was performed to identify the set of attributes, which better discriminate teams according to their classifications in an annual tournament.

\section{Subjects}

A total of 90 male basketball players (age, $13.80 \pm 0.33$ years, mean $\pm \mathrm{SD}$ ) and 102 female basketball players (age, $13.48 \pm$ 0.59 years, mean $\pm \mathrm{SD}$ ) were evaluated. These participants, 8 male and 9 female under-14 (U-14) elite regional teams of the First Portuguese division (i.e., teams composed of the players selected from each administrative region), took part in the 2016 Portuguese Festival of Youth Basketball. The Portuguese Festival of Youth Basketball is an annual tournament organized by the Portuguese Basketball Federation for 18 U-14 elite regional teams. The tournament is organized in 2 divisions (i.e., first and second) according to the ranking of previous year. The first division is composed by the 9 best-ranked teams of the previous year and second division is composed by the 9 lowestranked teams of the previous year. Both male and female first division teams have been divided into 3 groups according to its final classification in the tournament-finalists (teams classified in first or second place), semifinalists (teams classified in third and fourth place), and lower-ranked teams (comprised last 4 male and 5 female teams). The measurements took place on the first day of the tournament to avoid the influence of players' fatigue on the results of the measurements. However, some players were measured after the competition started. In these cases, it was guaranteed that the evaluations were carried out at least 2 hours after a game was played.

All participants received a clear explanation of aims and procedures of the study and signed informed consent documents were obtained for all subjects. Only the players, whose parents or legal guardians had signed an informed consent form, were permitted to participate in the study. The study was authorized by the Ethics Committee of the Faculty of Physical Education and Sport-Universidade Lusófona and performed according to the Declaration of Helsinki.

\section{Procedures}

The tests battery used in the study covered maturity, morphological, and fitness evaluation. 

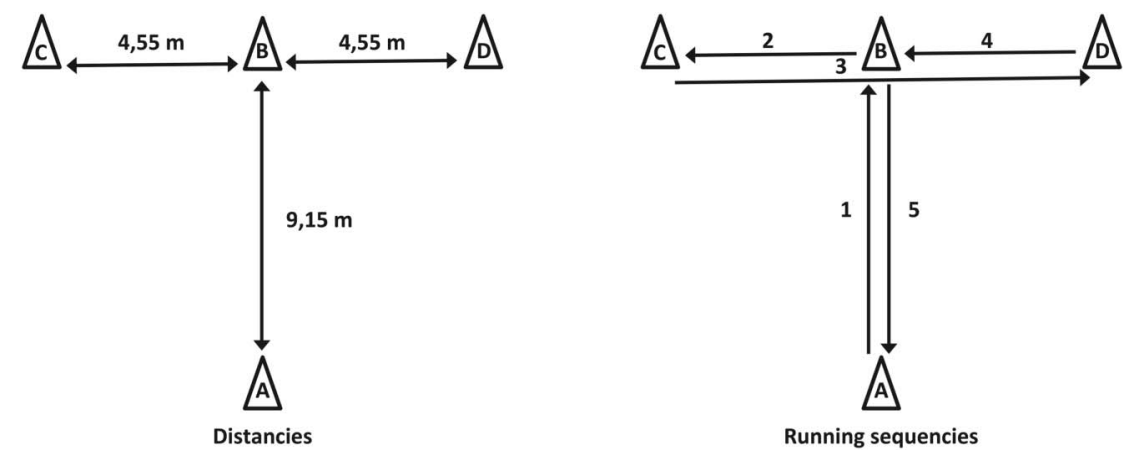

Figure 1. Schematic representation of the T-test.

Age and Maturity Evaluation. Chronological age (CA; in decimals) was calculated as the difference between date of birth and the date on which the anthropometric measures were taken.

Maturity offset (years before or after APHV, i.e., YAPHV) was predicted from a sex-specific equation based on Canadian and Belgian boys (28); maturity offset minus CA provided an estimate of APHV. The SEE of the equation was 0.592 (95\% CI 1.18 years) (28). Maturity offset (YAPHV) can be used to classify adolescents as pre- or post-APHV, whereas individuals can also be grouped by years before or after APHV rather than CA. Applicability of the method appears to be useful during the interval of growth spurt, approximately $12-15$ years (22).

Maturity offset was calculated, respectively as follows:

GIRLS: Maturity offset (years) $=-9.376+(0.0001882 \times$ $[$ Leg Length $\times$ Sitting Height $])+(0.0022 \times[$ Age $\times$ Leg Length $])+(0.005841 \times[$ Age $\times$ Sitting Height $])-$ $(0.002658 \times[$ Age $\times$ Weight $])+(0.07693 \times[$ Weight by Height Ratio $\times 100])$

BOYS: Maturity offset (years) $=-9.236+(0.0002708 \times$ $[$ Leg Length $\times$ Sitting Height $])+(-0.001663 \times[$ Age $\times$ Leg Length $])+(0.007216 \times[$ Age $\times$ Sitting Height $])+$ $(0.02292 \times[$ Weight by Height Ratio $\times 100])$. Note, the need to multiply the weight by height ratio by 100 was overlooked in the original publication (28). Predicted age at PHV (years) was calculated as the difference between CA and predicted maturity offset at observation (28).

Morphological Evaluation. Body mass, stature, sitting height, and 3 skinfolds (triceps, TRI; calf, GML; and subscapular, SBS) were measured following the International Society for the Advancement of Kinanthropometry (ISAK) protocol (23). Arm span was measured as a perpendicular distance between the longitudinal planes of the left and right dactylion, whereas hand span was measured as the greater distance between the longitudinal planes of the first and fifth fingers (24).
Body mass was measured, to the nearest $0.5 \mathrm{~kg}$, using a scale (Secca model 761 7019009, Vogel \& Halke, Germany). Stature and sitting height were measured to the nearest $\mathrm{mm}(0.1 \mathrm{~cm})$ using a Siber-Hegner anthropometric kit (DKSH Ltd., Zurich, Switzerland) and leg length was calculated from the difference of stature and sitting height. The 3 skinfolds were measured using a Rosscraft Slim Guide Skinfold caliper, which allows reading of millimeters up to the 10th (at a pressure on the tips of $10 \mathrm{mg} \cdot \mathrm{cm}^{-2}$ ). All measures were taken by 2 certified ISAK anthropometric technicians in a private and heated room within school facilities. Practitioner individual measurements were collected, in all subjects, by the same ISAK evaluators (Intraobserver technical error of measurements-TEM: stature, $R$ $\geq 0.98$; sitting height $R \geq 0.96$; skinfolds, between $R=$ [0.92-0.98]).

The body composition analysis included evaluation of fat mass (14), free-fat mass (14), and body mass index (BMI). The relative FM $(\% \mathrm{FM})$ and the FFM $(\mathrm{kg})$ were estimated from the value of skinfolds. The $\% \mathrm{FM}$ was calculated as the arithmetic mean of the $\% \mathrm{FM}$ values obtained through the equations proposed by Lohman (Equation $1: \% \mathrm{FM}=1: 35$ $[\mathrm{TRI}+\mathrm{SBS}]-0012[\mathrm{TRI}+\mathrm{SBS}]^{2}-\mathrm{I}$, and I = constant $)$ and Slaughter et al. (Equation 2: $\% \mathrm{FM}=0.735$ [TRI + GML] + 1) (33). Body mass index was calculated by the formula BMI $=$ Body mass $/$ Stature $^{2}$.

Fitness Evaluation. Before the fitness tests, all participants performed a 20-minute standardized warm-up routine (a slow jogging followed by static and dynamic stretching). The players were allowed 10 -minute passive rest between tests and water breaks and extra rest time. Each participant was verbally instructed and encouraged to give his/her maximal effort. All players completed 7 fitness tests, from which 9 variables were collected for analysis.

Speed Test. The 20-m speed test was performed according to the protocol described by Jakovljevic and coauthors (15) and 
TABLE 1. Descriptive statistics (mean $\pm S D$ ) and comparison by ANOVA of differences in maturational parameters, morphological, fitness characteristics, and training experience between finalists, semifinalists, and lower-ranked teams played in the male U-14 Portuguese national basketball championship.*

\begin{tabular}{|c|c|c|c|c|}
\hline & \multicolumn{4}{|c|}{ Male teams } \\
\hline & Finalists $N=24$ & Semifinalists $N=22$ & Lower-ranked $N=44$ & $p$ \\
\hline \multicolumn{5}{|l|}{ MATURITY } \\
\hline $\mathrm{CA}(\mathrm{y})$ & $13.84 \pm 0.38$ & $13.77 \pm 0.36$ & $13.79 \pm 0.30$ & 0.724 \\
\hline APVH (y) & $13.12 \pm 0.65$ & $13.27 \pm 0.59$ & $13.27 \pm 0.60$ & 0.593 \\
\hline YAPHV (y) & $0.72 \pm 0.74$ & $0.50 \pm 0.70$ & $0.52 \pm 0.66$ & 0.449 \\
\hline \multicolumn{5}{|l|}{ MORPHOLOGY } \\
\hline Body mass (kg) & $61.90 \pm 8.71$ & $61.52 \pm 7.72$ & $60.48 \pm 10.04$ & 0.807 \\
\hline Stature $(\mathrm{cm})$ & $174.79 \pm 8.07$ & $173.29 \pm 8.45$ & $173.12 \pm 8.49$ & 0.719 \\
\hline Arm span $(\mathrm{cm})$ & $178.07 \pm 8.41$ & $175.56 \pm 8.52$ & $177.48 \pm 10.13$ & 0.630 \\
\hline Hand span (cm) & $22.27 \pm 1.73$ & $22.00 \pm 1.57$ & $22.11 \pm 1.92$ & 0.871 \\
\hline $\mathrm{BMI}\left(\mathrm{kg} \cdot \mathrm{m}^{-2}\right)$ & $20.15 \pm 1.57$ & $20.44 \pm 1.60$ & $20.08 \pm 2.37$ & 0.785 \\
\hline$\% F M$ & $14.80 \pm 3.63$ & $17.29 \pm 4.45$ & $18.08 \pm 5.45$ & $0.029 \dagger$ \\
\hline Lean mass (kg) & $52.50 \pm 5.94$ & $50.70 \pm 5.41$ & $49.24 \pm 6.84$ & 0.128 \\
\hline \multicolumn{5}{|l|}{ FITNESS } \\
\hline V20-m (s) & $3.13 \pm 0.13$ & $3.19 \pm 0.16$ & $3.31 \pm 0.16$ & $<0.001 \ddagger \S$ \\
\hline $\mathrm{TT}(\mathrm{s})$ & $10.10 \pm 0.42$ & $10.30 \pm 0.48$ & $10.54 \pm 0.65$ & $0.010 \ddagger$ \\
\hline CMJ height $(\mathrm{cm})$ & $29.08 \pm 3.67$ & $30.04 \pm 3.39$ & $29.18 \pm 4.94$ & 0.712 \\
\hline CMJ power (W) & $736.2 \pm 122.4$ & $741.6 \pm 115.8$ & $733.7 \pm 147.8$ & 0.977 \\
\hline CMJA height $(\mathrm{cm})$ & $35.91 \pm 4.48$ & $34.5 \pm 4.32$ & $34.84 \pm 5.13$ & 0.573 \\
\hline CMJA power (W) & $818.4 \pm 137.5$ & $792.9 \pm 109.8$ & $802.4 \pm 159.2$ & 0.833 \\
\hline SUM HG (kg) & $74.56 \pm 13.73$ & $75.99 \pm 9.01$ & $76.44 \pm 16.77$ & 0.876 \\
\hline MBT (m) & $5.34 \pm 0.84$ & $5.07 \pm 071$ & $4.87 \pm 0.65$ & $0.041 \dagger$ \\
\hline Seat and reach $(\mathrm{cm})$ & $-1.13 \pm 9.25$ & $0.85 \pm 7.99$ & $-0.59 \pm 7.46$ & 0.698 \\
\hline \multicolumn{5}{|l|}{ TRAINING } \\
\hline Basketball experience (y) & $6.21 \pm 2.17$ & $5.92 \pm 2.38$ & $4.61 \pm 2.89$ & $0.029 \dagger$ \\
\hline Practice per week & $4.29 \pm 0.90$ & $4.17 \pm 1.01$ & $3.77 \pm 0.83$ & 0.052 \\
\hline Hours of practice per week & $6.56 \pm 1.62$ & $6.52 \pm 1.53$ & $6.17 \pm 2.01$ & 0.603 \\
\hline
\end{tabular}

${ }^{*} \mathrm{ANOVA}=$ Analysis of variance; $\mathrm{CA}=$ chronological age; $\mathrm{APHV}=$ age at peak height velocity; $\mathrm{YAPHV}=\mathrm{y}$ to age at peak height velocity; $\mathrm{BMI}=$ body mass index; $\% \mathrm{FM}=$ Fat mass percentage; $\mathrm{TT}=\mathrm{T}$-test; $\mathrm{V} 20-\mathrm{m}=$ Speed $20 \mathrm{~m}$ test; CMJ = countermovement jump; CMJA = countermovement jump with arm swing; $\mathrm{SUM} \mathrm{HG}=$ sum of right and left handgrip; $\mathrm{MBT}=$ medicine ball throw; $F F M=$ Free fat mass percentage; $\mathrm{SJ}=$ squat jump.

† Significant difference between finalist and lower-ranked teams, $p<0.05$.

$\ddagger$ Significant difference between finalist and lower-ranked teams, $p<0.01$

$\S$ Significant difference between semifinalist and lower-ranked teams, $p<0.01$.

consisted of a 20 -m race. All participants departed from a standing position. The time of speed test was recorded in seconds and hundredths of second using photoelectric cells (Wireless Sprint system; Brower Timing Systems, Salt Lake City, UT, USA). The best time of 2 attempts was registered. The intraclass correlation coefficient (ICC) for the speed test was $r=0.937(p<0.001)$.

T-Test. T-test was used for the agility assessment $(10,15)$. Performing the test participants started from the standing position at the final line of the basketball court, sprinted 9.15-m in straight line touching the cone A, slipped into defensive position and touched the cone $\mathrm{B}$ that was 4.55$\mathrm{m}$ away to the left from cone $\mathrm{A}$, slided defensively to cone $\mathrm{C}$, which was at $4.55-\mathrm{m}$ distance to the right of the cone A (9.10-m from cone B), defensively slided back to the cone
$\mathrm{A}$, which was at $4.55-\mathrm{m}$ from cone $\mathrm{C}$ and ran backward to the starting line (15). The time of T-test test was recorded in seconds and hundredths of second using photoelectric cells (Wireless Sprint system; Brower Timing Systems). The best time of 2 attempts was registered. Figure 1 provides an overview of the test procedure. The ICC for the T-test was $r=$ $0.962(p<0.001)$.

Jump Tests. The explosive and elastic leg strength were tested throughout counter movement jump (CMJ) and counter movement jumps with arm (CMJA) swing, following the protocol described by Bosco et al. (3). The height $(\mathrm{cm})$ and power (Watts, W) of vertical jumps were recorded with an Chronojump measurement technology (Bosco System, Globus, Italy). The best record of 2 attempts was recorded. In both tests, the retry interval was 10 seconds. For the CMJ,

4 Journal of Strength and Conditioning Research 
TABLE 2. Descriptive statistics (mean $\pm S D$ ) and comparison by ANOVA of differences in maturational parameters, morphological, fitness characteristics, and training experience between finalists, semifinalists, and lower-ranked teams played in the female U-14 Portuguese national basketball championship.*

\begin{tabular}{|c|c|c|c|c|}
\hline & \multicolumn{4}{|c|}{ Female teams } \\
\hline & Finalists $N=21$ & Semifinalists $N=22$ & Lower-ranked $N=59$ & $p$ \\
\hline \multicolumn{5}{|l|}{ MATURITY } \\
\hline CA (y) & $13.51 \pm 0.45$ & $13.68 \pm 0.46$ & $13.40 \pm 0.65$ & 0.139 \\
\hline APVH (y) & $11.93 \pm 0.47$ & $11.90 \pm 0.29$ & $11.87 \pm 0.42$ & 0.823 \\
\hline YAPHV (y) & $1.59 \pm 0.40$ & $1.79 \pm 0.41$ & $1.53 \pm 0.53$ & 0.155 \\
\hline \multicolumn{5}{|l|}{ MORPHOLOGY } \\
\hline Body mass (kg) & $52.59 \pm 6.31$ & $57.05 \pm 6.70$ & $56.14 \pm 8.60$ & 0.144 \\
\hline Stature $(\mathrm{cm})$ & $164.34 \pm 7.09$ & $165.75 \pm 4.01$ & $163.83 \pm 6.67$ & 0.475 \\
\hline Arm span $(\mathrm{cm})$ & $166.17 \pm 7.58$ & $168.42 \pm 4.99$ & $165.91 \pm 7.59$ & 0.360 \\
\hline Hand span (cm) & $20.84 \pm 1.18$ & $20.36 \pm 0.97$ & $20.43 \pm 1.17$ & 0.297 \\
\hline BMI $\left(\mathrm{kg} \cdot \mathrm{m}^{-2}\right)$ & $19.51 \pm 1.89$ & $20.73 \pm 1.97$ & $20.88 \pm 2.69$ & 0.081 \\
\hline$\% \mathrm{FM}$ & $22.56 \pm 3.45$ & $23.82 \pm 2.45$ & $23.51 \pm 4.27$ & 0.511 \\
\hline Lean mass (kg) & $40.68 \pm 3.89$ & $43.39 \pm 4.59$ & $42.68 \pm 5.08$ & 0.147 \\
\hline \multicolumn{5}{|l|}{ FITNESS } \\
\hline V20-m (s) & $3.50 \pm 0.20$ & $3.40 \pm 0.11$ & $3.55 \pm 0.13$ & $0.001 \dagger$ \\
\hline $\mathrm{TT}(\mathrm{s})$ & $11.23 \pm 0.60$ & $10.95 \pm 0.42$ & $11.35 \pm 0.52$ & $0.012 \dagger$ \\
\hline CMJ height $(\mathrm{cm})$ & $23.85 \pm 4.28$ & $23.58 \pm 2.73$ & $22.81 \pm 3.34$ & 0.426 \\
\hline CMJ power (W) & $574.9 \pm 73.7$ & $616.3 \pm 71.7$ & $597.8 \pm 85.5$ & 0.244 \\
\hline CMJA height $(\mathrm{cm})$ & $27.95 \pm 4.88$ & $27.61 \pm 3.11$ & $26.40 \pm 3.53$ & 0.196 \\
\hline CMJA power (W) & $621.4 \pm 67.5$ & $666.4 \pm 71.8$ & $643.1 \pm 88.3$ & 0.194 \\
\hline SUM HG $(\mathrm{kg})$ & $58.07 \pm 6.61$ & $63.27 \pm 6.87$ & $56.85 \pm 13.25$ & 0.070 \\
\hline MBT $(m)$ & $3.93 \pm 0.33$ & $4.12 \pm 0.34$ & $3.76 \pm 0.43$ & $0.001 \dagger$ \\
\hline Seat and reach $(\mathrm{cm})$ & $2.78 \pm 6.83$ & $5.92 \pm 7.51$ & $3.13 \pm 7.55$ & 0.273 \\
\hline \multicolumn{5}{|l|}{ TRAINING } \\
\hline Basketball experience (y) & $4.75 \pm 2.77$ & $5.38 \pm 2.44$ & $4.43 \pm 2.85$ & 0.383 \\
\hline Practice per week & $3.96 \pm 0.86$ & $4.08 \pm 0.88$ & $3.75 \pm 1.07$ & 0.346 \\
\hline Hours of practice per week & $6.06 \pm 1.37$ & $6.85 \pm 1.88$ & $5.77 \pm 2.61$ & 0.144 \\
\hline
\end{tabular}

${ }^{*} \mathrm{ANOVA}=$ Analysis of variance; $\mathrm{CA}=$ chronological age; $\mathrm{APHV}=$ age at peak height velocity; YAPHV $=y$ to age at peak height velocity; $\mathrm{BMI}=$ body mass index; \%FM = Fat mass percentage; $\mathrm{TT}=\mathrm{T}$-test; $\mathrm{V} 2 \mathrm{O}-\mathrm{m}=$ Speed $20 \mathrm{~m}$ test; CMJ = countermovement jump; CMJA = countermovement jump with arm swing; SUM HG = sum of right and left handgrip; MBT = medicine ball throw; FFM = Free fat mass percentage; $\mathrm{SJ}=$ squat jump.

$\dagger$ Significant difference between semifinalist and lower-ranked teams, $p<0.01$

the participant was allowed a downward movement by rapidly bending and extending their knees to jump as high as possible. During the CMJ, the participant maintained their trunk in an upright posture and their hands on hips to eliminate the influence of arm swing. For the CMJA, the participant was allowed to swing their arms backward (during the downward movement) and then forward and upwards (during the push-off phase). The ICC for height and power of CMJ test was $r=0.976(p<0.001)$ and $r=0.994(p<0.001)$, respectively. The ICC for height and power of CMJA test was $r=0.986(p<0.001)$ and $r=0.996(p<0.001)$, respectively.

2-Kg Medicine Ball Throw. The upper-limb explosive strength was tested using the 2-kg medicine ball throw (MBT). Participants started the test from a sitting position with the back against the wall using a release from the chest. The distance $(\mathrm{cm})$ attained in the best of 2 attempts was recorded. Medicine ball throw was used in similar studies to measure the explosive upper-body strength $(10,31)$. The ICC for the 2-kg MBT test was $r=0.982(p<0.001)$.

Handgrip Strength. The handgrip strength was assessed with the handgrip test using a dynamometer (Takei Physical Fitness Test, TKK 5001, GRIP-A). Participants performed the test twice with each hand, and the sum of best results achieved by left and right hand was considered (in $\mathrm{kg}$ ). The ICC for the right and left handgrip test was $r=0.990$ $(p<0.001)$ and $r=0.989(p<0.001)$, respectively.

Sit and Reach Test. The flexibility was assessed using the sit and reach test. Each subject was seated barefoot on the floor with legs out straight ahead and with their feet placed with the soles flat against the sit and reach box. With hands on 
TABLE 3. Adjusted descriptive statistics (mean $\pm S E$ ) and comparison by MANCOVA (practice experience as covariant) of differences in morphological and fitness characteristics between finalists, semifinalists, and lowerranked teams played in the male U-14 Portuguese national basketball championship.*

\begin{tabular}{|c|c|c|c|c|}
\hline & \multicolumn{4}{|c|}{ MANCOVA (BE $\dagger)$} \\
\hline & Finalists $N=24$ & Semifinalists $N=22$ & Lower-ranked $N=44$ & $p$ \\
\hline \multicolumn{5}{|c|}{ MORPHOLOGY } \\
\hline$\% F M$ & $14.87 \pm 1.12$ & $18.01 \pm 1.22$ & $18.39 \pm 0.84$ & $0.042 \ddagger$ \\
\hline \multicolumn{5}{|l|}{ FITNESS } \\
\hline V20-m (s) & $3.13 \pm 0.03$ & $3.21 \pm 0.03$ & $3.31 \pm 0.02$ & $<0.001 \S$ \\
\hline $\mathrm{TT}(\mathrm{s})$ & $10.10 \pm 0.12$ & $10.41 \pm 0.13$ & $10.54 \pm 0.09$ & $0.019 \ddagger$ \\
\hline MBT (m) & $5.38 \pm 0.15$ & $5.05 \pm 0.15$ & $4.86 \pm 0.11$ & $0.029 \ddagger$ \\
\hline
\end{tabular}

$* \% \mathrm{FM}=$ Fat mass percentage; $\mathrm{V} 20-\mathrm{m}=$ Speed $20 \mathrm{~m}$ test; $\mathrm{TT}=\mathrm{T}$-test; MBT $=$ medicine ball throw.

†Covariant: Basketball experience (BE) $=5.292$.

Significant difference between finalist and lower-ranked teams, $p<0.05$.

$\S$ Significant difference between finalist and lower-ranked teams, $p<0.01$.

top of each other and palms facing down, each player tried to reach forward along the measuring line as far as possible. The score of the test was recorded to the nearest centimeter as the distance reached by the tip of the fingers. The vertical line of the feet soles was considered as a plane counted as the 0 centimeters. Negative and positive centimeters were considered when players reached forward, respectively, before and after this vertical plane. The ICC for seat and reach flexibility test was $r=0.990(p<0.001)$.

\section{Statistical Analyses}

The Statistical Package for the Social Sciences software (SPSS version 21.0, Chicago, IL, USA) was used for statistical calculations. Significance level was set at $5 \%$ with effect sizes (partial eta square) also calculated. The outliers were identified for each variable within groups using simple boxplot method, and then the assumptions of normality and equality of variance were tested by Shapiro-Wilk test and the Levene's test, respectively.

Descriptive statistics (mean, M; standard deviation, $S D$ ) for teams of both sexes were calculated. Players were spread into 3 groups according to the final classifications of their team, i.e., finalists (classified in first to second place), semifinalists (classified in third or fourth place), and lower-ranked teams (classified from fifth to eighth positions for male teams and from fifth to ninth positions for female teams). The significant differences among the average maturity, morphologic, and fitness variables between 3 groups of players were evaluated using 1-way analysis of variance followed by a multiple comparisons test (Tukey HSD). The variables, for which significant differences have been identified between groups, were used in the stepwise discriminant function analysis to determine what set of variables better discriminated each groups of players. The assumption of equality of the group covariance matrices was checked by Box's $M$ test.

6 Journal of Strength and Conditioning Research

\section{RESUlts}

Table 1 presents maturational parameters, morphological, and fitness characteristics of better- and lower-ranked teams played in the male U-14 Portuguese National Basketball Championship in 2015-2016 season.

No significant differences were observed for CA, APHV, and YAPHV between male finalists, semifinalists, and lowerranked teams (Table 1).

The morphological evaluation showed that the $\% \mathrm{FM}$ was the only morphological variable significantly different between 2 male groups. Finalist players showed lower-body fat percentage than lower-ranked players $(F(2,87)=3.687$,

TABLE 4. Summary of standardized canonical discriminant function coefficients, eigenvalues, and correct classification cases for male (finalists) and female (semifinalists) and lowerranked regional teams played in the men's and women's under-14 Portuguese national basketball championship in 2015-2016 season.*

\begin{tabular}{lcc}
\hline & Male teams & Female teams \\
\hline 20-M sprint (s) & 1.000 & 0.769 \\
MBT (m) & - & -0.616 \\
Eigenvalue & 0.336 & 0.416 \\
Cases correctly & 76.1 & 81.8 \\
$\quad$ classified & $\wedge=0.749$ & $\wedge=0.706$ \\
Function & $\chi^{2}(1)=$ & $\chi^{2}(1)=$ \\
& $18.661 \dagger$ & $25.765 \dagger$ \\
\hline & ${ }^{\star M B T}=$ Medicine Ball Throw test. \\
& & \\
& &
\end{tabular}


$p=0.029$; partial $\left.\eta^{2}=0.078\right)$. However, no significant differences were observed between finalist and semifinalist players for $\% \mathrm{FM}$ or other morphological variables.

Regarding fitness evaluations, male players from finalist teams performed significantly better in sprint $(F(2,84)=$ 12.575, $p<0.001$; partial $\left.\eta^{2}=0.23\right)$, agility $(F(2,84)=$ 4.849, $p=0.010$; partial $\left.\eta^{2}=0.104\right)$, and MBT tests $(F$ $(2,86)=3.324, p=0.041$; partial $\left.\eta^{2}=0.072\right)$ than players from lower-ranked teams (Table 1). Semifinalist players were significantly faster than players from lower-ranked teams. No differences were observed in fitness variables between finalist and semifinalist male players.

Table 2 indicates no significant differences were observed in CA, APHV, and YAPHV between female players from finalist, semifinalist, and lower-ranked teams. The morphological measurements also did not reveal any significant differences between the 3 female groups.

Regarding the fitness variables, female players from semifinalist teams were significantly faster $(F(2,95)=7.743, p=$ 0.008 ; partial $\left.\eta^{2}=0.140\right)$, more agile $(F(2,95)=4.627$, $p=0.012$; partial $\left.\eta^{2}=0.089\right)$, and stronger in MBT $(F$ $(2,95)=7.164, p=0.001$; partial $\left.\eta^{2}=0.131\right)$ than female players from lower-ranked teams, as can be seen in Table 2. No significant differences were found between the finalist and semifinalist teams in any fitness test performed.

After the assessment of differences between 3 groups of teams, 2 stepwise discriminant analyses were performed: for male teams, between finalists and lower-ranked teams; for female teams, between semifinalists and lower-ranked teams. The results of stepwise discriminant analysis applied to the fitness variables have identified the following variables which significantly better discriminated male team finalists and female semifinalists from lower-ranked male and female teams: (a) speed and (b) the combination of speed and upper-body strength (measured by MBT), respectively (Tables 3 and 4).

\section{Discussion}

In the present study, we have identified differences in body composition (only in males) and physiological attributes (both males and females) in young basketball players with different performances in a championship.

No significant differences in maturation and anthropometric attributes have been identified between the 3 groups of teams of both sexes.

It is common knowledge that basketball is a team sport, where anthropometric factors (i.e., body mass, stature, arm span) play an important role in adult player and team performances $(16,30)$. Previous studies reported significant differences in stature, arm span, leg length, and hand length between elite and nonelite young basketball players $(13,36)$. Frequently, these differences are related to different maturity status of evaluated players, having early maturing practitioners bigger body sizes and better performances in physical tests than late maturing players $(6,35,37)$. The contribution of growth and maturation to anthropometric characteristics, functional capacity, and performance of adolescent players is well documented in literature on different sports games $(8,25)$. In ages of a high rate of growth and a faster acquisition of physical skills (which is the case of players of our study, particularly boys), small differences in biological maturation may imply substantial differences in motor and physical abilities, and consequently, may influence game performance. Coelho e Silva et al. (6) found that among 14-year-old male basketball players, those who achieved a mature state were $17 \mathrm{~cm}$ taller and $31.3 \mathrm{~kg}$ heavier compared with players in midpuberty. Torres-Unda et al. (37) also found that teams, which obtained better results in a championship, tended to be "more mature" than teams which performed worse. The same authors found an association between players' maturity status (evaluated by YAPHV) and the individual performance (evaluated by Performance Index Rating, PIR, and points scored) in a Spanish Basketball Association Championship (37). However, contrary to this trend, the results of our study showed no significant differences in maturity (i.e., APHV and YAPHV) and anthropometric variables (i.e., weight, stature, arm span, hand span) between players from finalists, semifinalists, and lower-ranked teams. The fact that the 3 groups of teams were very similar in biological maturation (i.e., APHV and YAPHV) may explain the similar results found in height, weight, and arm span. However, results of this study regarding maturity should be interpreted cautiously. The Mirwald method (28), used in the present study, despite being widely used to estimate the maturity offset of players (35) has some limitations well documented in the literature (20).

Surprisingly, stature was not an important factor for the teams' final classification in the championship-no significant differences were found for height between the 3 groups of both sexes. A recent study conducted with young basketball players of the same age category also has not found any significant differences in height among 3 groups of teams with different classification in the Spanish Basketball Association Championship (37).

These results suggest that contrary to the adult basketball players $(4,39)$, stature does not differentiate young basketball players of higher- and lower-classified U-14 teams (37). These results are in line with the findings of several studies that also failed to identify the significant contribution of maturity, height, and body mass to the sport-specific performance of adolescent players (40).

At the same time, it should be noted that the athletes selected for regional teams are on average taller (in boys +10 $\mathrm{cm}$; in girls $+8 \mathrm{~cm}$ ) and heavier (in boys $+5 \mathrm{~kg}$; in girls +4.5 $\mathrm{kg}$ ) than the normal Portuguese population at these ages (32). This fact suggests that height and weight are the important attributes for youth basketball, and these attributes were considered by the youth coaches in players' selection process for Portuguese basketball regional teams. However, when compared to male Spanish players of the same age 
category, our male sample shows lower mean values of weight $(-6 \mathrm{~kg})$, height $(-7 \mathrm{~cm})$, and arm span $(-4 \mathrm{~cm})$ (37). The same tendency was found in female players. Portuguese adolescent players showed lower values of weight $(-6.6 \mathrm{~kg})$ and height $(-8.3 \mathrm{~cm})$ when compared to top elite European players (12).

Morphological measurements have been widely used in the evaluation of male and female adolescent players $(6,17,34)$. Despite the importance of these evaluations for the characterization of young players' profile and their evolution during the specializing years (9), measurements do not reflect the whole range of factors that influence team performance in basketball and so do not differentiate the young player according their skill level.

The $\%$ fat was the only morphologic variable to show significant difference between players from finalists and lower-ranked male teams, with higher values of adiposities for lower-classified players. It is reasonable to suppose that higher adiposity affects players' running and jumping capacities, what can negatively be reflected on the game performance in basketball (29). Therefore, control of body fat in young players may be an important factor for improving individual and team performances (36).

Regarding fitness attributes, significant differences were identified among young players. Male finalist players were significantly faster than players from semifinalist and lowerranked teams. Comparing to players from lower-ranked teams, the finalists were also more agile and stronger (threw the medicine ball over a longer distance). Players from semifinalist female teams significantly outperformed their lower-positioned peers in speed, agility, and upper-body strength.

Speed and agility are considered crucial attributes of basketball performance in both adult (14) and in youth teams $(13,15,34)$. For instance, Hoare (13) when studying 248 athletes (125 males and 123 females) of the U-16 category, who participated in the Australian National Championship, found that speed was a differentiating variable between elite and nonelite female players.

Agility is an essential attribute in basketball because of a great number of atypical game situations that request from players multiple and rapid changes of displacement direction and body position in the relatively small space of the court. Agility is often correlated with speed, which also influences considerably basketball performance $(1,15)$. Our results are consistent with the findings of previous research, showing that male players from better-ranked teams are faster and more agile than players from lower-ranked teams. On the contrary, female finalist players were not faster and more agile than semifinalist or lower-ranked teams. Female differences were only observed between semifinalists and lowerranked teams. This finding suggests that the difference in final team classification can be hypothetically explained by superior technical and tactical skills of finalist female players, and also may indicate that these components of performance are determinant for the competitive result in youth female basketball.

In both sexes, differences were also observed in the 2-kg MBT between players from better- and lower-ranked teams. Male finalist players threw the $2-\mathrm{kg}$ medicine ball over a longer distance than did lower-ranked players. The same result was also observed for female semifinalists and lowerranked players. Santos and Janeira (31) suggest that synchronization and coordination levels of upper-body segments and a greater muscular strength are relevant for a more effective skill domain in MBT. Particularly in 13-14-year-old players that have less muscular strength and greater difficulties to shoot the ball from longer distances than the adult players, upper limb strength may contribute to the improvement of basketball shooting technique and, consequently, influence the whole team performance.

Our results can suggest that speed, agility, and upper-body strength can be seen as important attributes for basketball performance and the evaluation of these motor skills, based on 20-m running, T-test and 2-kg MBT tests, should be included in talent development programs.

Previous research pointed out strength and power of lower limbs as a fundamental quality for basketball performance, especially when it evaluated by vertical jump height $(16,30)$. The results of our study have not confirmed any significant differences in jump performance in $\mathrm{CMJ}$ and CMJA between players of higher- and lower-ranked teams, both male and female. The evaluation of handgrip strength also has not differentiated players according to their final classification in the championship.

Regarding the second aim of our study, the stepwise discriminant analyses revealed that: (a) in male teams, speed per se discriminated finalist players from lower-ranked players with a correct classification of $76.1 \%$ of cases; (b) in female teams, a combination of upper-body strength and speed discriminated semifinalists from lower-ranked players. These results enhanced the importance of speed in youth basketball performance, especially for boys, and suggest that upper-body strength associated with a specific technical gesture (i.e., passing or shooting) can be a determinant factor for player and team performances, particularly in female teams.

In summary, the findings of this study pointed out that (a) speed, agility, and upper limbs' explosive strength differentiated adolescent male and female players from higher- and lower-ranked regional Portuguese basketball teams, (b) speed was revealed as a crucial factor for discrimination of male players according to their final classification group, whereas the upper limbs' explosive strength and speed have been identified as important factors to discriminated female higher-ranked from lower-ranked players.

Our results confirm that some fitness tests (particularly, 20-m, T-test and MBT) are associated with final rankings of adolescent basketball teams, but further research is needed to better understand how maturational, anthropometric, and physical attributes influence the individual performance in 
youth basketball and how these data could be used in the early stages of talent development and in prediction of future achievements of young practitioners.

\section{Practical Applications}

Although it is unclear to what extent the maturational, morphological, and fitness attributes of adolescent basketball players can predict their future performances, there is no doubt that regular players' evaluation provides coaches with useful information about the evolution of young athletes and may contribute to more adequate mid- and long-time practice planning.

The results of the present study highlighted the speed ability and the explosive arms' strength for young females, and the speed for young males as the discriminators of shortterm performance of basketball players. Associated with socalled "adolescent spurt" $(19,38)$, these results open an important window of opportunity $(18,26)$ for basketball coaches of this age category. Coaches should introduce the athletic development of the young players as an important part of the training plan. At this practice level, coaches should combine the sport-specific basketball drills with the speed and agility purposes. These specific drills might be achieved by increasing of the quickness, the simple and the composite reaction time using the laterality of ball handling as a criterion of execution, particularly on the pass and dribble fundamentals. Considering that the U-14 level is a primary stage of any basketball training program, it is desirable that players should be encouraged to run over the frequent defensive-offensive transitions, to produce efficient fast-break shots, and to play with intensive and pressure behaviors over the ball handlers in the defensive phase of the game.

\section{ACKNOWLedGments}

The authors have no competing interests to declare. No funding was received for this work.

\section{REFERENCES}

1. Ben-Abdelkrim, N, Chaouachi, A, Chamari, K, Chtara, M, and Castagna, C. Positional role and competitive-level differences in elite-level men's basketball players. J Strength Cond Res 24: 13461355, 2010.

2. Beunen, G and Malina, R. Growth and biological maturation: Relevance to athletic performance. In: The Child and Adolescent Athlete. O Bar-Or, ed. Oxford, United Kingdom: Blackwell Publishing, 2005, pp. 3-17.

3. Bosco, C, Luhtanen, P, and Komi, PA. Simple method for measurement of mechanical power in jumping. Eur J Appl Physiol 50: 273-282, 1983

4. Carter, JEL, Ackland, TR, Kerr, DA, and Stapff, AB. Somatotype and size of elite female basketball players. J Sports Sci 23: 1057-1063, 2005.

5. Coelho e Silva, M, Carvalho, H, Gonçalves, C, Figueiredo, A, Elferink-Gemser, M, Philippaerts, R, et al. Growth, maturation, functional capacities and sport-specific skills in 12-13-year-old basketball players. J Sports Med Phys Fitness 50: 174-181, 2010.

6. Coelho e Silva, M, Figueiredo, A, Carvalho, HM, and Malina, RM. Functional capacities and sport-Specific skills of $14-15$ year old male basketball players: Size and maturity effects. Eur J Sport Sci 8: 277-285, 2008.

7. Coelho e Silva, M, Figueiredo, A, Gonçalves, C, Vaz, V, and Malina, R. Crescimento, maturação e performance no contexto da formação desportiva [in Portuguese]. Revista Portuguesa de Ciências do Desporto 4: 91-94, 2004

8. Coelho e Silva, M, Vaz, V, Simões, F, Carvalho, H, Valente dos Santos, J, Figueiredo, A, et al. Sport selection in under-17 male roller hockey. J Sports Sci 30: 1793-1802, 2012.

9. Cotê, J, Baker, J, and Abernethy, B. Practice and play in the development of sport expertise. In: Handbook of Sport Psychology. G Tenenbaum and RC Ecklund, eds. Hoboken, NJ: Wiley, 2007. pp. 184-202.

10. Delextrat, A and Cohen, D. Strength, power speed and agility of women basketball players according to playing position. J Strength Cond Res 23: 1974-1981, 2009.

11. Drinkwater, E, Pyne, D, and Mckenna, M. Design and interpretation of anthropometric and fitness testing of basketball players. $J$ Sports Med 38: 565-578, 2008.

12. Erčulj, F, Blas, M, and Bračič, M. Physical demands on young elite European female basketball players with special reference to speed, agility, explosive strength, and take-off power. J Strength Cond Res 24: 2970-2978, 2010.

13. Hoare, D. Predicting success in junior elite basketball players the contribution of anthropometric and physiological attributes. $J S c i$ Med Sport 3: 391-405, 2000.

14. Hoffman, J, Tenenbaum, G, Maresh, C, and Kreamer, W. Relationship between athletic performance tests and playing time in elite college basketball players. J Strength Cond Res 10: 67-71, 1996.

15. Jakovljevic, S, Karalejic, M, Pajic, Z, Macura, M, and Erculz, F. Speed and Agility of 12 and 14-year-old elite male basketball players. $J$ Strength Cond Res 26: 2453-2459, 2012.

16. Karpowicz, K. Interrelation of selected factors determining the effectiveness of training in young basketball players. Hum Movement 7: 130-146, 2006.

17. Lidor, R, Cote, J, and Hackfort, D. ISSP position stand: To test or not to test? The use of physical skill tests in talent detection and in early phases of sport development. International Journal of Sport and Exercise Psychology, 9, 131-146. Int J Sport Exerc Psychol 9: 131-146, 2009.

18. Lloyd, RS and Oliver, JL. The youth physical development model: A new approach to long-term athletic development. Strength Cond J 34: 61-72, 2012.

19. Malina, RM, Rogol, AD, Cumming, S, Coelho e Silva, M, and Figueiredo, A. Biological maturation of youth Athletes: Assessment and implications. Br J Sports Med 49: 852-859, 2015.

20. Malina, R, Coelho e Silva, M, Figueiredo, A, Carling, C, and Beunen, G. Interrelationships among invasive and non-invasive indicators of biological maturation in adolescent male soccer players. J Sports SCi 30: 1705-1717, 2012.

21. Malina, RM, Bouchard, C, and Bar-Or, O. Growth Maturation and Physical Activity. Champaign, IL: Human Kinetics, 2004.

22. Malina, RM and Koziel, SM. Validation of maturity offset in a longitudinal sample of Polish girls. J Sports Sci 32: 1374-1382, 2014.

23. Marfell-Jones, M, Olds, T, Stewart, A, and Carter, J. International Standards for Anthropometric Assessment (Revised 2006). Underdale, SA: International Society for the Advancement of Kinanthropometry, 2006.

24. Massuça, L and Fragoso, I. A multidisciplinary approach of success in team-handball. Apunts Medicina de l'Esport 48: 143-151, 2013.

25. Matthys, S, Vaeyens, R, Coelho e Silva, M, Lenoir, M, and Philippaerts, R. The contribution of growth and maturation in the functional capacity and skill performance of male adolescent handball players. Int J Sports Med 33: 543-549, 2012. 
26. McNarry, M, Barker, A, Lloyd, RS, Buchheit, M, Williams, C, and Oliver, J. The BASES expert statement on trainability during childhood and adolescence. Sport Exerc Scientist 41: 22-23, 2014.

27. Meylan, C, Cronin, J, Oliver, J, and Hughes, M. Talent identification in soccer: The role of maturity status on physical, physiological and technical characteristics. Int J Sports Sci Coaching 5: 571-592, 2010.

28. Mirwald, RL, Baxter-Jones, AD, Bailey, DA, and Beunen, GP. An assessment of maturity from anthropometric measurements. Med Sci Sports Exerc 34: 689-694, 2002.

29. Nikolaidis, P, Asadi, A, Santos, E, Calleja-González, J, Padulo, J, Chtourou, $\mathrm{H}$, et al. Relationship of body mass status with running and jumping performances in young basketball players. Muscles Ligaments Tendons J 5: 187-194, 2015.

30. Ostojic, S, Mazic, S, and Dikic, N. Profiling in basketball: Physical and physiological characteristics of elite players. J Strength Cond Res 20: 640-744, 2006.

31. Santos, E and Janeira, M. Effects of complex training on explosive strength in adolescent male basketball player. J Strength Cond Res 22: 903-909, 2008.

32. Santos, R, Mota, J, Santos, DA, Silva, AM, Baptista, F, and Sardinha, LB. Physical fitness percentiles for Portuguese children and adolescents aged 10-18 years. J Sports Sci 32: 1510-1518, 2014.

33. Slaughter, MH, Lohman, TG, Boileau, RA, Horswill, CA, Stillman, RJ, Van Loan, MD, et al. Skinfold equations for estimations of body fatness in children and youth. Hum Biol 60: 709-723, 1988.
34. Štrumbelj, E and Erčulj, F. Analysis of experts' quantitative assessment of adolescent basketball players and the role of anthropometric and physiological attributes. J Hum Kinetics 42: 267-276, 2014.

35. Te Wierike, S, Elferink-Gemser, M, Tromp, E, Vaeyens, R, and Visscher, C. Role of maturity timing in selection procedures and in the specialisation of playing positions in youth basketball. $J$ Sports Sci 33: 337-345, 2014.

36. Torres-Unda, J, Zarrazquin, I, Gil, J, Ruiz, F, Irazusta, A, Kortajarena, $\mathrm{M}$, et al. Anthropometric, physiological and maturational characteristics in selected elite and non-elite male adolescent basketball players. J Sports Sci 31: 196-203, 2013.

37. Torres-Unda, J, Zarrazquin, I, Gravina, L, Zubero, J, Seco, J, Gil, SM, et al. Basketball performance is related to maturity and relative age in elite adolescent players. $J$ Strength Cond Res 30: 1325-1332, 2016.

38. Viru, A, Loko, J, Harro, M, Volver, A, Laaneots, L, and Viru, M. Critical periods in development of performance capacity during childhood and adolescence. Eur J Phys Education 4: 75-119, 1999.

39. Ziv, G and Lidor, R. Physical attributes, physiological characteristics, on-court performances and nutritional strategies of female and male basketball players. J Sports Med 39: 547-568, 2009.

40. Ziv, G and Lidor, R. Anthropometrics, physical characteristics, physiological attributes, and sport-specific skills in under-14 athletes involved in early phases of talent development-A review. $J$ Athletic Enhancement 3: 1-5, 2014. 